\title{
EBD-CPD: Evidence-based Dentistry Continuing Professional Development
}

\author{
Derek Richards \\ Editor, Evidence-Based Dentistry
}

The journal is launching a website to help to enable readers to record and verify the time they have spent studying articles in this journal. Here we outline how to do this.

Evidence-Based Dentistry (2003) 4, 42. doi:10.1038/sj.ebd.6400185

How to access and use the website:

\section{Step 1. Log on}

Having connected to the Internet, enter the address of the website: www.nature. com/ebd/cpd

This will take you to the sign-on page.

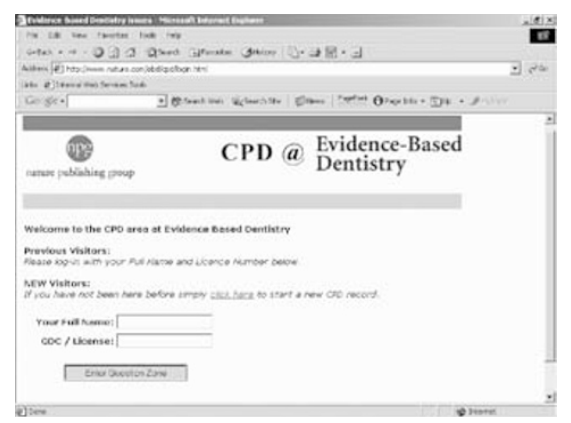

\section{Step 2. Sign on}

The Sign-on page will prompt you to enter your General Dental Council (GDC) number or state licence number. This will then take you to welcome page.

\section{Step 3. Welcome!}

At the "welcome" you will be presented with a list of available question sets. If you have completed sets of questions previously you will also see a list of question sets that you have completed, for example.
You have completed the following CPD question set(s):

CPD Question Set 1 - EBD Volume 4 Issue No. 2

CPD Question Set 2 - EBD Volume 4 Issue No. 3

- Click on one of the above links to retrieve previous answers and certificates You have yet to complete the following questions set(s):

CPD Question Set 3 - EBD Volume 4 Issue No. 4

CPD Question Set 4 - EBD Volume 5 Issue No. 1

- Click on one of the above links to begin a new set of questions

Clicking on question sets that you have answered previously will take you to a file called "previous answers". This will show the answers you gave along with the correct answers. Clicking

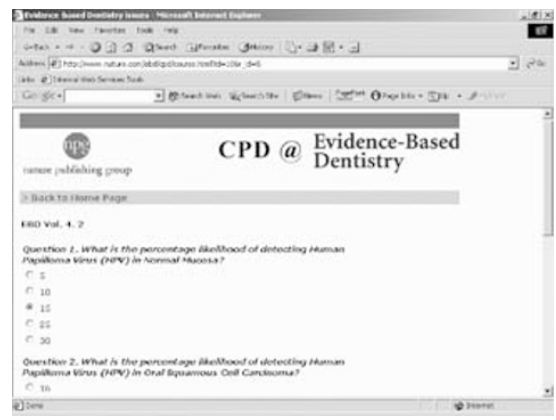

on the yet-to-be-completed questions sets will take you to the questionnaire page.

\section{Step 4. The questions}

On the question page you will see a number of multiple-choice questions. The questions will be based on the content of one particular issue of the journal. Answer each of the questions and when you are finished press the finish button. You will be taken to the answers page.

\section{Step 5. The answers}

The answers page will show both your answer and the correct answer. Hopefully they will be the same! Some answers also contain additional information.

From the answers page you will be able to print out your answers and a certificate which will include your name and GDC/Licence number for CPD records.

The accompanying article by Alan Lawrence provides some pointers for how you can make the best of your CPD opportunities.

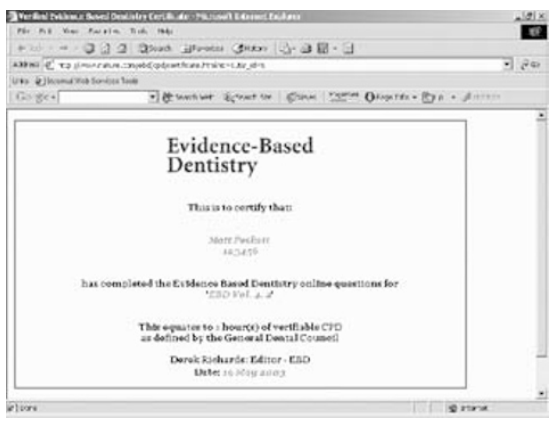

